Proceedings of the Seminar on the Social and Economic Effects

of Earthquake Prediction, 12 October, 1977.

\title{
THE IMPLICATIONS OF EARTHQUAKE PREDICTION FOR THE NEW ZEALAND ELECTRICITY DEPARTMENT
}

\author{
M. T. O'Brien*
}

\section{INTRODUCTION}

The New Zealand Electricity Department's overall objective is the production of a reliable, continuous and safe supply of electricity at the lowest practical cost to meet New Zealand's current and long-term social and economic requirements. Being a nation wide generation and transmission system, the generating stations and power supply substations are well spread throughout both islands and are all interconnected via long transmission lines.

Any serious earthquake within New Zealand is likely to stress some part of the power system. The consequences to both the public and the Department on each such occasion depends on a number of factors. While electrical equipment has generally been designed to cope with earthquakes, the design requirements have improved over the years as the earthquake engineering knowledge has increased. Advance warning, of earthquakes which are likely to have some impact on the supply of electricity, may enable action to be taken to minimise any foreseeable consequences.

\section{SOCIAL IMPIICATIONS OF AN INTERRUPTION OR REDUCTION IN ELECTRICITY SUPPLY}

In the event of a serious earthquake, power supply may be interrupted to one or more areas because of damage to transmission lines or substation equipment. Alternatively, supply may be limited because of the reduced ability of part of the supply network to carry the required load, or because of the reduced ability of the generation plant to meet the required load. A reduction in generation capacity may necessitate a corresponding reduction in total load, but this would be spread over as many areas as possible to minimize the number of people with severe reductions.

In most homes electricity is essential for lighting, cooking, food storage, hot water and some space heating. In many urban areas it is essential for water and sewage pumping. It is also vital to many commercial and industrial organisations to enable staff to be employed, and the standard of care and comfort in hospitals and other health services is dependant on a continuous supply of electricity.

While a reduction in quality or quantity of electricity can be handled in a number of ways; such as supplying at reduced voltage and frequency or by reducing the hot water heating load with the assistance of local power supply authorities; interruptions to supply have such a

\footnotetext{
* New Zealand Electricity Department
}

significant impact on society that restoration of supply, even to a limited extent, is an overriding priority.

\section{ECONOMIC IMPLICATIONS OF AN INTERRUPTION OR REDUCTION IN ELECTRICITY SUPPLY}

In electricity dependant manufacturing and processing industries, including the frozen food, dairying and poultry industries, the consequences of an interruption in electricity supply, particularly if sustained for days, can result in substantial financial losses. The losses may be important both locally and nationally. Such situations are only likely to arise where damage, as a result of an earthquake, seriously delays the restoration of even a partial electricity supply. Within the power system, damage to major regional interconnecting transmission lines may necessitate the operation of the more expensive thermal generating plant instead of lower cost hydro generating plant to maintain electricity supply. Water may have to be released over spillways, and not used for generation because of transmission restrictions.

In August 1975 the Benmore-Haywards $500 \mathrm{kV}$ HVDC transmission line collapsed, over a $3 \mathrm{~km}$ length near sheffield, during an exceptionally severe storm. Until the

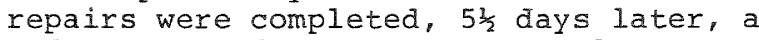
reduced but adequate power supply was maintained to the North Island public by the increased use of thermal generating plant, the use of some North Island water storage earlier than previously planned and assisted by the energy conservation efforts of the public. The total cost (direct plus indirect costs) were of the order of $\$ 1.5$ million to the Department.

Also, within the power system earthquake damage to lake shorelines as a result of earthquake initiated subsidence, or damage to an earth dam may restrict the rate at which water can be subsequently drawn from the lake for power generation. The weakening of any civil water retaining structure may require the urgent release of stored water without using it. In these kinds of situations a valuable energy resource may be unusable or wasted, and its replacement generation from thermal stations may be a very expensive venture and may involve fuels with high overseas value.

Damage to gas pipelines, steam pipelines, or coal conveyor systems may necessitate the shutdown of complete generating stations. Depending on the time of the year there may be no sources of replacement generation to satisfy the normal electricity demand.

\section{POSSIBLE BENEFITS OF EARTHQUAKE}




\section{PREDICTION}

At present, whenever an earthquake corresponding to M.M. V or greater on the Modified Mercalli Scale is felt by station staff, inspections are carried out, on a wide range of power system equipment, in accordance with an established set of guidelines. The information being gained from this is enabling the more earthquake vulnerable equipment or parts of the power system to be identified so that any worthwhile action can be taken to minimise possible future consequences.

Emergency procedures already exist to deal with any unexpected emergencies within the power system, which may arise from any cause, including earthquakes. These procedures include the operation of the power system outside its normal target values of voltage and frequency, and beyond normal ratings, as well the co-ordination of resources and facilities to carry out repairs.

Advance warning of earthquakes in general would enable more intensive monitoring of the behaviour of parts of the power system, even for moderate earthquakes, and advance preparations of planning to cope with any foreseeable consequences.

\subsection{Hydro-Generation}

Advance warning of any earthquake centre near part of the hydro generating system would enable planned observations of the behaviour of the relevant dams, reservoirs, and hydraulic equipment to be made, and possioly automatic water level recorders could be set up in strategic positions. The information, from automatic recordings, may assist in providing safety warnings to the public in downstream areas, or to other stations lower down in the hydro system if the unexpected release of large volumes of water occurred from a major reservoir.

The degrees of control the Department can exercise over the hydro lakes is limited and slow to take effect. Undoubtedly, if it was known with sufficient certainty that a particular dam was threatened by a major earthquake, action to reduce the water level behind the dam would be initiated. However, it must be recognized that in most cases water can be transferred only from one reservoir to the next and at a limited rate. Also, the social and economic consequences of dewatering a lake can be severe. The Department has done this in the past for weed control, but only to a limited extent and only for certain lakes, and with long planning times involved. To a lesser extent lake levels have been adjusted in advance of high inflows expected from meteorological forecasts, to minimize likely flooding consequences.

The Department already has considerable knowledge of the geology of its sites and earthquake warnings would be assessed with regard to this background and action may well vary from site to site according to the proximity of fault lines, etc.

\subsection{Thermal Generation}

If major earthquakes were forecast to occur near thermal stations, it may be desirable to unload coal conveyor systems, to take certain high pressure steam lines out of service, or to empty large fuel-oil storage tanks. It may be very difficult to find an acceptable place to transfer the oil to, and in fact such action may not be necessary as considerable earthquake resistance is built into most large tanks.

A thermal station could be shut down if the risk was high, imminent and reasonably certain.

\subsection{Transmission Lines and Substations}

While it is seldom likely that transmission line towers would fail structurally in an earthquake, landslip, or subsidence may cause the collapse of a section of a transmission line. Major ground movement in the Inangahua earthquake left the transmission line through the area undamaged, but with one tower perched close to the edge of a precipice which previously did not exist.

The obvious precautions to take regarding transmission lines would be first those relevant to public safety, e.g. increased patrols especially where transmission lines cross highways and housing areas and secondly to ensure resources were increased in the region so that if necessary temporary sections of transmission line could be erected on guyed towers or wood poles as quickly as possible should damage occur.

Where substations are unmanned, it may be desirable to locate operating staff nearby to attend to any unforeseen problems which may arise with the station equipment. Contingency plans for subsequent operation of a station with temporary arrangements using a limited part of the station equipment and operating outside its normal ratings could be prepared to minimize interruption durations.

\subsection{Power Station and Substation Construction}

Equipment in the partially assembled state is often more vuinerable to damage than at any other time. For example, generator stator windings may be set on temporary supports on the open machine hall floor while being assembled. In the event of a major earthquake warning, steps would naturally be taken to firmly secure all equipment in a temporarily vulnerable state until the emergency has passed.

\section{CONCLUSION}

In general the occasions on which significant damage occurs resulting in lengthy interruptions to electricity supply, or in lengthy reductions in the availability of generating plant, should be few and far between. Any satisfactory earthquake prediction system should enable the most effective use of resources to minimize both the social and economic consequences by allowing preparation for prompt restoration of supply and for re-allocation of energy storage to best overall advantage in the circumstances. 
The approval of the General Manager, New Zealand Electricity Department, to publish this paper is acknowledged.

\section{APPENDIX}

(a) Earthquake Resistant Design Criteria Within New Zealand Electricity Department

Since 1970 all equipment purchased and installed has been required to be able to withstand earthquake shaking of intensity IX on the Modified Mercalli scale. The dynamic characteristics of all items is assessed at the tendering stage.

A large proportion of the equipment purchased prior to 1970 had a satisfactory level of earthquake resistance. A programme to confirm the adequacy of the existing equipment, and to modify equipment where necessary commenced in the mid $1960^{\prime} \mathrm{s}$ when the supporting platforms for the mercury-arc $A C / D C$ converter values at Haywards and Benmore were strengthened.

Civil engineering assessments of the hydro dams indicates their resistance to earthquakes is much better than the power station buildings and other equipment.

Thermal power stations are complex to assess in terms of earthquake resistance. However, special computer programmes have been developed and are being used in the design of the large Huntly power station.

(b) Behaviour of the Power System Electrical Equipment during Earthquakes

Except in cases where damage actually occurs to items of equipment, the electrical equipment generally continues to perform its function without difficulty. However, violent shaking may cause transmission line conductors to clash together establishing electrical fault conditions which are cleared by normal protective action. All important transmission line circuits are provided with automatic switching (automatic re-closing) so that the consequences on power supply are negligible. Some kinds of protective relays are prone to operate unnecessarily when shaken. Where operation of relays of this type can cause unwanted interruptions to supply during earthquakes, either additional 'aseismic' relays are installed in conjunction to 'disconnect' the appropriate tripping circuits, or alternative designs of relays are being adopted. 